\title{
BACTERICIDAL STUDIES OF PENICILLIN-GENTAMICIN COMBINATIONS AGAINST GROUP B STREPTOCOCCI
}

\author{
Gary D. Overturf, Marc Horowitz, Jeanette Wilkins, \\ JoHn LeEDom and Evan Steinberg \\ Department of Pediatrics and Internal Medicine and the Hastings Foundation \\ Infectious Disease Laboratory of the University of Southern California and the \\ Los Angeles County-University of Southern California Medical Center, \\ Los Angeles, California, U. S. A.
}

(Received for publication March 28, 1977)

\begin{abstract}
The bactericidal activity of penicillin-aminoglycoside combinations was studied in 16 strains of Group B streptococci. Minimal inhibitory concentrations (MIC) against kanamycin or gentamicin were greater than $50 \mu \mathrm{g} / \mathrm{ml}$, whereas ampicillin or penicillin inhibitory concentrations were uniformly less than $0.1 \mu \mathrm{g} / \mathrm{ml}$. Although all strains had bactericidal concentrations (MBC) less than $0.1 \mu \mathrm{g}$ penicillin/ml, penicillin at a concentration equal to each strains respective $\mathrm{MBC}$ reduced inoculum colony forming units (CFU) 2 logs in only 6 of 16 strains in bactericidal kinetic studies. However, the addition of gentamicin in concentrations of 5.0 or $10.0 \mu \mathrm{g} / \mathrm{ml}$ to penicillin markedly enhanced bactericidal activity in all strains tested. The addition of lower concentrations of gentamicin $(1.0 \mu \mathrm{g} / \mathrm{ml})$ had minimal advantage over penicillin alone. No distinct advantage was noted for combinations including either ampicillin or kanamycin. The theoretical advantage of penicillin-aminoglycoside combinations in experimental conditions, suggests that the use of antibiotic combinations in clinical infections due to Group B streptococci, may result in a more rapid eradication of these organisms.
\end{abstract}

A number of in vitro and in vivo studies have suggested the greater bactericidal activity of penicillins when combined with aminoglycosides (synergy) against a wide variety of microorganisms, particularly Group D streptococci ${ }^{1,2,3)}$, staphylococci $^{4)}, E$. coli $^{5)}$ and pseudomonas species ${ }^{6,7)}$. Also, the use of penicillin-aminoglycoside combinations has been advocated for clinical entities such as streptococcal and staphylococcal endocarditis, pseudomonas septicemia and the syndrome of neonatal sepsis.

The recent increase in the frequency of infections due to Group B streptococci in neonates has been recorded by others ${ }^{8,9)}$. Prior studies ${ }^{9,10)}$ of in vitro susceptibility of these organisms to antibiotics have emphasized their marked susceptibility to penicillins, with minimal inhibitory concentrations consistently less than $0.05 \mu \mathrm{g}$ benzyl-penicillin/ml. However, neither the bactericidal activity of penicillins against Group B streptococci nor the potential synergy of penicillin-aminoglycoside combinations has received attention. These combinations are frequently chosen for use against infections in the neonate, including septicemia and meningitis. Therefore, in vitro susceptibility studies of Group B streptococci were done to determine if there is any potential advantage to the use of penicillin-aminoglycoside combinations in treatment of clinical infections due to these organisms.

Supported in part by: The Hastings Foundation Fund.

Reprint request to: Gary D. Overturf, M. D., Hastings Infectious Disease Laboratory, 1129 North State Street, Room 2G24, Los Angeles, California 90033, U. S. A.

Presented in part to: The Streptococcal Club, 16th International Conference on Antimicrobial Agents and Chemotherapy,Chicago, Illinois, September 23, 1976. 


\section{Materials and Methods}

Bacteriology: Sixteen strains of Group B streptococci, isolated from CSF from infants with neonatal meningitis, were studied. All strains demonstrated the typical colony morphology and hemolytic patterns of Group B streptococci, and were typed by standard methods ${ }^{11}$. All strains were submitted for subtyping*: thirteen strains were type III and one each was type II, IB and Ia.

Susceptibility Studies: Susceptibility studies were performed against benzyl penicillin (PCN), ampicillin (AMP), kanamycin (KM), and gentamicin (GM). Minimal inhibitory concentrations (MIC) were determined by inoculation of strains into serial two-fold antibiotic dilutions $(200 \sim 0.025 \mu \mathrm{g} / \mathrm{ml})$ in tryptic soy broth (Difco). The inoculum size for MIC determinations was standardized to contain approximately $10^{5}$ organisms and results of all susceptibility studies were read after 20-hour incubation in $5 \% \mathrm{CO}_{2}$ at $37^{\circ} \mathrm{C}$. The MIC was defined as the lowest concentration of antibiotic which yielded no visible growth after incubation. The minimal bactericidal concentrations (MBC) was determined for each strain by inoculation onto a sheep blood agar plate of $0.01 \mathrm{ml}$ from each tube from the serial dilution without visible growth, and for the purposes of this study, the MBC was defined as the lowest concentration which yielded less than 10 colonies after incubation. Representative colonies which persisted beyond the defined $\mathrm{MBC}$ were picked and resubmitted to susceptibility testing to exclude the possibility that these represented resistant clones.

Bactericidal Studies: Bactericidal curves were constructed by performing serial counts of colony forming units (CFU) beginning at the time of inoculation into $30 \mathrm{ml}$ of tryptic soy broth $\left(10^{5}\right.$ bacteria/ $\mathrm{ml}$ ) and at 2, 4, 6 and 20 hours thereafter (Fig. 1). Cultures were incubated at $37^{\circ} \mathrm{C}$ in $5 \% \mathrm{CO}_{2}$. The concentration of benzylpenicillin (or ampicillin) used in constructing each bactericidal curve was always at the pre-determined MBC. A concentration of gentamicin (or kanamycin) of $10.0 \mu \mathrm{g} / \mathrm{ml}$ was utilized initially in studies against all 16 strains; lower concentration $(1.0$ or $5.0 \mu \mathrm{g} / \mathrm{ml})$ were utilized in selected strains which were markedly susceptible to gentamicin at the higher concentrations. All organisms inoculated without added antibiotics achieved $10^{8 \sim 9} \mathrm{CFU} / \mathrm{ml}$ at 20 hours. Curves were constructed against all 16 strains of Group B streptococci grown without added antibiotic (control) and against organisms grown in gentamicin, benzylpenicillin and benzylpenicillin-gentamicin combinations. Bactericidal activity of ampicillin, kanamycin and the combination of ampicillin-kanamycin or ampicillingentamicin was similarly studied in a few representative strains.

Table 1. MIC and MBC, 16 strains of Group B streptococci against benzylpenicillin G

\begin{tabular}{l|c|c|c|c}
\hline Strain & Subtype & $*$ MIC & $*$ MBC (10 colonies) & $\begin{array}{c}\text { *MBC } \\
\text { (No growth) }\end{array}$ \\
\hline $72-109$ & Ia & .025 & .05 & 0.4 \\
$72-150$ & III & .05 & .05 & 12.5 \\
$72-178$ & III & .025 & .025 & 0.5 \\
$72-319$ & III & .05 & .10 & 12.5 \\
$73-72$ & III & .10 & .10 & 3.13 \\
$75-200$ & III & .05 & .10 & 3.13 \\
$75-240$ & II & .05 & .05 & 6.25 \\
$75-450$ & III & .05 & .05 & 50 \\
$76-5$ & III & .025 & .10 & 25 \\
$76-6$ & III & .10 & .10 & 50 \\
$76-7$ & III & .025 & .025 & 25 \\
$76-9$ & III & .025 & .025 & 25 \\
$76-10$ & Ib & .050 & .050 & 3.13 \\
$76-11$ & III & .025 & .025 & 1.6 \\
$76-12$ & III & .025 & .05 & 0.8 \\
$76-13$ & III & .10 & .10 & 50 \\
\hline
\end{tabular}

* Concentration in $\mu \mathrm{g}$ benzylpenicillin $/ \mathrm{ml}$

* Subtyping was performed by Dr. Bascom Anthony, Department of Pediatrics, Harbor General Hospital, UCLA School of Medicine. 


\section{Results}

All strains were markedly susceptible to benzylpenicillin in routine susceptibility studies with MIC's and MBC's uniformly equal to, or less than, $0.10 \mu \mathrm{g} / \mathrm{ml}$ (Table 1). Results with ampicillin were similar

Fig. 1. Comparative growth curves of organisms grown without antibiotics or in penicillin $(0.2 \mu \mathrm{g} /$ $\mathrm{ml})$, gentamicin $(10.0 \mu \mathrm{g} / \mathrm{ml})$ and penicillin-gentamicin combinations in strain No. 75-450.

Bactericidal curves, strain No. $75-450$ Group B streptococcus

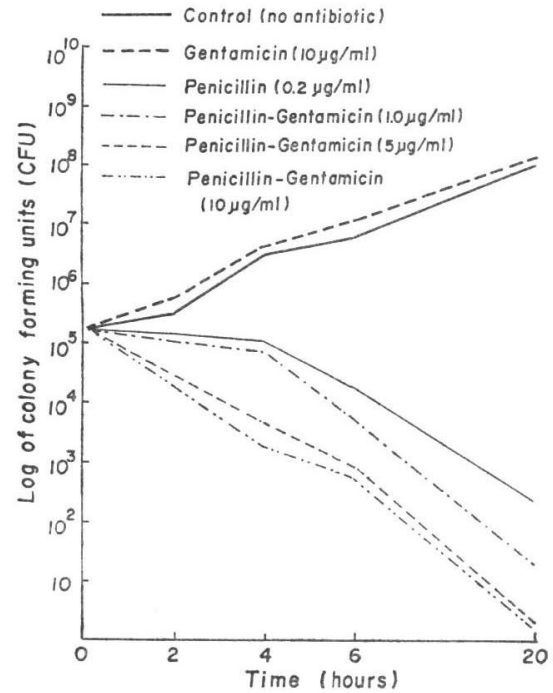

to benzylpenicillin. However, the majority of strains demonstrated a "persistence" phenomenon on bactericidal testing against penicillins. Persistent colonies were present at $3 \sim 4$ dilutions beyond the defined $\mathrm{MBC}$ despite rigid adherence to an inoculum of $10^{5}$ organisms $/ \mathrm{ml}$. Eight of 16 strains had colonies at concentrations $\geq 12.5$ $\mu \mathrm{g} / \mathrm{ml}$ during bactericidal testing. However, if the MBC had been defined at the lowest concentration yielding no growth, only three of 16 strains would have had MBC's less than 1.0 $\mu \mathrm{g} / \mathrm{ml}$. Subculture and repeat susceptibility testing of representative persistent colonies failed to identify any clones of intrinsically resistant strains.

MIC's and MBC's were consistently greater than $50 \mu \mathrm{g} / \mathrm{ml}$ for gentamicin, (range 50 200 $\mu \mathrm{g} / \mathrm{ml})$. Kanamycin was slightly less active with MBC's against all strains greater than $200 \mu \mathrm{g} / \mathrm{ml}$.

In bactericidal studies, penicillin at a concentration equal to each strain's respective $\mathrm{MBC}$,

Table 2. Log reduction of inoculum colony counts $(\mathrm{CFU} / \mathrm{ml})$ at 20 hours of incubation by benzylpenicillin and gentamicin alone and in combination

\begin{tabular}{c|c|c|c}
\hline Strain No. & Penicillin (PCN)* & Gentamicin $(\mathrm{GM})^{* *}$ & PCN-GM** \\
\hline $72-109$ & -1.2 & 0 & -5.0 \\
$76-5$ & -1.9 & 0 & -5.0 \\
$76-6$ & -2.0 & 0 & -5.0 \\
$76-7$ & -0.8 & 0 & -5.0 \\
$73-72$ & -1.8 & 0 & -5.0 \\
$72-319$ & -2.0 & 0 & -5.0 \\
$72-150$ & -1.7 & 0 & -5.0 \\
$72-178$ & -3.4 & 0 & -5.0 \\
$76-11$ & -2.0 & 0 & -5.0 \\
$76-10$ & 0 & 0 & -5.0 \\
$76-12$ & -1.8 & 0 & -5.0 \\
$76-9$ & -1.9 & 0 & -5.0 \\
$75-240$ & -1.1 & 0 & -5.0 \\
$75-200$ & -2.8 & 0 & -5.0 \\
$75-450$ & -2.6 & 0 & -5.0 \\
$76-13$ & -1.8 & 0 & -5.0 \\
\hline
\end{tabular}

* Penicillin concentration at the determined MBC for each strain in all experiments

** Gentamicin concentration, $10.0 \mu \mathrm{g} / \mathrm{ml}$. 
Table 3. Log reduction of inoculum $\mathrm{CFU} / \mathrm{ml}$ at 20 hours with variable concentrations of gentamicin with penicillin

\begin{tabular}{c|c|c|c|c|c}
\hline Strain No. & PCN* & GM (10)+ & PCN-GM (1.0)+ & PCN-GM (5.0)+ & PCN-GM (10.0)+ \\
\hline $76-5$ & -1.9 & 0 & -2.8 & -5.0 & -5.0 \\
$76-7$ & -0.8 & 0 & -3.5 & -5.0 & -5.0 \\
$73-72$ & -1.8 & 0 & -3.0 & -5.0 & -5.0 \\
$76-13$ & -2.6 & 0 & -4.0 & -5.0 & -5.0 \\
\hline
\end{tabular}

* Penicillin concentrations at the determined $\mathrm{MBC}$ for each strain in all experiments.

( ) $+=$ concentration of gentamicin in $\mu \mathrm{g} / \mathrm{ml}$.

Table 4. Log reduction of inoculum colony counts $(\mathrm{CFU} / \mathrm{ml})$ at 20 hours of incubation by combinations including ampicillin, benzylpenicillin and kanamycin

\begin{tabular}{|c|c|c|c|c|}
\hline Strain No. & Ampicillin (AM)* & GM $(10.0)+$ & $\mathrm{AM}+\mathrm{GM}(1.0)+$ & $\mathrm{AM}+\mathrm{GM}(10.0)+$ \\
\hline \multirow{3}{*}{$\begin{array}{l}76-5 \\
76-6\end{array}$} & -1.2 & 0 & -3.1 & -5.0 \\
\hline & -2.6 & 0 & -3.0 & -5.0 \\
\hline & $\mathrm{AM}$ & \multicolumn{2}{|l|}{ KM $(10.0)+$} & $\mathrm{AM}+\mathrm{KM}(10.0)+$ \\
\hline $76-5$ & -1.2 & \multicolumn{2}{|l|}{0} & -4.1 \\
\hline $76-6$ & -2.6 & \multicolumn{2}{|l|}{0} & -3.8 \\
\hline $76-7$ & -1.2 & \multicolumn{2}{|l|}{0} & -4.0 \\
\hline & $\mathrm{PCN}^{*}$ & \multicolumn{2}{|l|}{$\mathrm{KM}(10.0)+$} & $\mathrm{PCN}+\mathrm{KM}(10.0)+$ \\
\hline $76-5$ & -1.9 & \multicolumn{2}{|l|}{0} & -5.0 \\
\hline $76-6$ & -2.0 & \multicolumn{2}{|l|}{0} & -5.0 \\
\hline $76-7$ & -0.8 & \multicolumn{2}{|l|}{0} & -4.2 \\
\hline
\end{tabular}

* Ampicillin or penicillin concentration at the determined MBC for each strain in all experiments.

( ) $+=$ concentration of gentamicin or kanamycin in $\mu \mathrm{g} / \mathrm{ml}$

(defining the $\mathrm{MBC}$ as the lowest concentration yielding less than $10 \mathrm{CFU}$ at 20 hours), failed to reduce inoculum CFU/ml greater than 2 logs in 20 hours in 10 of 16 strains (Table 2). Benzylpenicillin did reduce inoculum $\mathrm{CFU} / \mathrm{ml}$ at least 2 logs in six strains, but counts of less than $10 \mathrm{CFU} / \mathrm{ml}\left(10^{1}\right)$ were never achieved in any strain with penicillin alone. In contrast, addition of gentamicin in high concentrations $(10 \mu \mathrm{g} / \mathrm{ml})$ to penicillin enhanced bactericidal activity in every strain, reducing all counts to less than $10 \mathrm{CFU} / \mathrm{ml}$.

In addition to the reduced number of CFU's at 20 hours with penicillin-gentamicin combinations compared to penicillin alone, in 4 of 16 strains the combination achieved less than $10 \mathrm{CFU} / \mathrm{ml}$ in 6 hours. These four strains were tested at combinations of penicillin and gentamicin with lower concentrations of gentamicin $(1.0$ or $5.0 \mu \mathrm{g} / \mathrm{ml})$ to determine if bactericidal activity was retained at concentrations of gentamicin more readily achieved in vivo (Table 3). In these strains, similar bactericidal activity was retained at $5.0 \mu \mathrm{g}$ gentamicin $/ \mathrm{ml}$, but only minimal enhancement of bactericidal activity was noted when gentamicin was at a concentration of $1.0 \mu \mathrm{g} / \mathrm{ml}$.

Combinations which included ampicillin had little advantage or disadvantage over benzylpenicillin (Table 4). Combinations including kanamycin at concentrations of $10.0 \mu \mathrm{g} / \mathrm{ml}$ were slightly less bactericidal than those combinations which included gentamicin. 


\section{Discussion}

Benzylpenicillin and ampicillin had good in vitro activity against Group B streptococci as determined by inhibitory concentrations (MIC). In contrast, gentamicin and kanamycin alone had very poor activity. The values for the determined MIC's of the penicillins and aminoglycosides reported here are similar to those reported by others ${ }^{9,10,12)}$. More recent studies by SEVERIN and WILEY ${ }^{13)}$ have suggested a steady increase in the relative resistance to penicillin of Group B streptococci from 1968 till the present. In contrast, BAKER and co-workers ${ }^{14)}$ found no consistent decrease in the susceptibility of Group B streptococci over a period of two decades.

Marked persistence during bactericidal testing (MBC) against penicillins was noted despite standardization of inoculum size to $10^{5}$ organisms. Persistence is a commonly observed phenomenon in susceptibility testing of antibiotics which are active against bacterial cell walls and the phenomenon is frequently exaggerated by variation in inoculum size. As noted, persistent colonies resubmitted to susceptibility testing had similar MIC's as the parent strains. Although the effect of variation of inoculum size was not examined specifically, it is possible that Group B streptococci may be markedly susceptible to these variations and small changes undetectable by standard colony counts accounted for the persistence observed.

Failure to reduce the number of organisms to less than $10 \mathrm{CFU} / \mathrm{ml}$ at 20 hours in bactericidal studies was demonstrated when benzylpenicillin or ampicillin was tested alone. The addition of gentamicin in high concentration $(10 \mu \mathrm{g} / \mathrm{ml})$ to either penicillin enhanced bactericidal activity in all strains tested, reducing CFU to less than 10 colonies $/ \mathrm{ml}$ but the addition of gentamicin in lower concentrations $(1.0 \mu \mathrm{g} /$ $\mathrm{ml}$ ) failed to consistently reduce colony counts to this level. No antagonism was noted with any combination of antibiotics tested. Kanamycin was slightly less active than gentamicin, in the limited number of strains tested. SCHAUF and co-workers ${ }^{15}$ ) have recently reported bactericidal killing kinetics in Group B streptococci with combinations of ampicillin and gentamicin; these investigators noted results similar to those reported here with accelerated killing by the combinations compared to either antibiotic alone.

Other investigators ${ }^{6,10)}$ have suggested that synergism must be defined by at least a 100 -fold ( 2 logs $\mathrm{CFU} / \mathrm{ml}$ ) or a $99.9 \%$ reduction of colony forming units caused by the combination as compared with the most effective single antibiotic. By this definition, the combination of benzylpenicillin or ampicillin with gentamicin at a concentration of $10 \mu \mathrm{g} / \mathrm{ml}$, was synergistic in all strains compared to either penicillin alone. Similar effects on bactericidal activity was noted in all four strains tested against the combination of benzylpenicillin and gentamicin at concentrations of $5.0 \mu \mathrm{g} / \mathrm{ml}$.

It can be anticipated that serum concentrations of penicillin and occasionally gentamicin would equal or exceed those employed in this study. A theoretical advantage of penicillin-gentamicin combination in the treatment of infections associated with Group B streptococcal septicemia is apparent. However, even in the presence of inflammation, penicillin may not uniformly attain high CSF concentrations and the variation of achieved concentrations may be marked ${ }^{16)}$. Similarly, concentrations of gentamicin in CSF are rarely greater than $4.0 \mu \mathrm{g} / \mathrm{ml}$ following systemic administration alone ${ }^{17}$. Because of these pharmokinetic limitations, the full significance of the observed in vitro synergism of penicillin and relatively high concentrations of gentamicin is unknown, particularly in regard to the treatment of central nervous system infections. However, because of the theoretical advantage of combined therapy, the combination may perhaps be indicated during the initial phase of treatment of meningitis. However, prolonged use of potentially toxic aminoglycosides cannot be justified on the basis of these limited in vitro studies.

\section{Acknowledgements}

The authors would like to acknowledge Ms. HeAtHer Wren and Mr. Ronald Ressler for technical assistance, Ms. ARLene Silva for the manuscript preparation and Dr. BASCOM ANTHONY for serotyping our strains of Group B streptococci. 


\section{References}

1) Fekety, F. R. \& P. Weiss: Antibiotic synergism: Enhanced susceptibility of enterococci to combinations of streptomycin and penicillins or cephalosporins. Antimicr. Agents \& Chemoth. -1965: 156 164, 1966

2) KIrby, WM. M.: Antibiotic synergism against enterococci. J. Infect. Dis. 122: 462 463, 1970

3) Glew, R. H.; R. C. Moerlling \& C. Wennersten: Comparative synergistic activity of nafcillin, oxacillin and methicillin in combination with gentamicin against enterococci. Antimicr. Agents \& Chemoth. 7: $828 \sim 832,1975$.

4) SANDE, M. A. \& M. L. Johnson: Antimicrobial therapy of experimental endocarditis caused by S. aureus. J. Inf. Dis. 131: $367 \sim 376,1975$

5) McCraken, G. H.: The rate of bacteriologic response to antimicrobial therapy in neonatal meningitis. Amer. J. Dis. Child. 123: $547 \sim 552,1972$

6) Kluge, R. M.; H. C. Standiford, B. Tatum, V. M. Young, W. H. Greene, S. C. Schimpff, F. M. Calia \& R. B. Hornick: Comparative activity of tobramycin, amikacin and gentamicin alone and with carbenicillin against Pseudomonas aeruginosa. Antimicr. Agents \& Chemoth. 6: 442 446, 1974

7) Libke, R. D.; C. Regamey, J. T. Clarke \& W. M. Kirby: Synergism of carbenicillin and gentamicin against enterococci. Antimicr. Agents \& Chemoth. 4: $564 \sim 568,1973$

8) Baker, C. J.; F. F. Barnett, R. C. Gordon \& M. D. Yow: Suppurative meningitis due to streptococci of Lancefield group B. A study of 33 infants. J. Pediat. 82: 724 729, 1973

9) Eickhoff, T. C.; J. O. Klein, A. K. Daly, D. Ingall \& M. Finland: Neonatal sepsis and other infections due to group B beta-hemolytic streptococci. New Eng. J. Med. 271: 1221 1228, 1964

10) Jones, W. F.; H. A. Feldman \& M. Finland: Susceptibility of hemolytic streptococci other than those of Group D to eleven antibiotics in vitro. Am. J. Med. 27: 159 169, 1957

11) Rantz, L. A. \& E. RANDALl: Use of autoclaved extracts of hemolytic streptococci for serological grouping. Stanford Med. Bull. 13: 290 291, 1955

12) Anthony, B. \& N. F. Concepcion: Group B streptococcus in a general hospital. J. Inf. Dis. 132: $561 \sim$ 567, 1976

13) Severin, M. J. \& J. L. Wiley: Change in susceptibility of Group B streptococci to penicillin G from 1968 through 1975. Antimicr. Agents \& Chemoth. 10: 380 381, 1976

14) Baker, C. J.; B. J. WebB \& F. F. Barrett: Antimicrobial susceptibility of Group B streptococci isolated from a variety of clinical sources. Antimicr. Agents \& Chemoth. 10: 128 131, 1976

15) Schauf, V.; A. DeVeikis, L. Raft \& A. Serota: Antibiotic killing kinetics of Group B streptococci. J. Pediat. 89: 194 198, 1976

16) Wilson, H. D. \& K. C. Haltalin: Ampicillin in H. influenzae meningitis. Amer. J. Dis. Child. 129: 208 218, 1975

17) McCraken, G. H. \& S. G. Mize: A controlled study of intrathecal antibiotic therapy in gram negative enteric meningitis of infancy. J. Pediat. 89: 66 72, 1976 